\title{
Customized recommendations for production management clusters of North American automatic milking systems
}

\author{
Marlène Tremblay, ${ }^{* 1}$ Justin P. Hess, ${ }^{*}$ Brock M. Christenson, ${ }^{*}$ Kolby K. McIntyre, ${ }^{*}$ Ben Smink, $\dagger$ \\ Arjen J. van der Kamp, $\ddagger$ Lisanne G. de Jong, $\ddagger$ and Dörte Döpfer* \\ *Department of Medical Sciences, Food Animal Production Medicine Section, School of Veterinary Medicine, University of Wisconsin-Madison, \\ 2015 Linden Drive, Madison 53706 \\ †Lely North America, 775 250th Avenue, Pella, IA 50219 \\ fLely International N.V., Cornelis van der Lelylaan 1, 3147 PB, Maassluis, the Netherlands
}

\section{ABSTRACT}

Automatic milking systems (AMS) are implemented in a variety of situations and environments. Consequently, there is a need to characterize individual farming practices and regional challenges to streamline management advice and objectives for producers. Benchmarking is often used in the dairy industry to compare farms by computing percentile ranks of the production values of groups of farms. Grouping for conventional benchmarking is commonly limited to the use of a few factors such as farms' geographic region or breed of cattle. We hypothesized that herds' production data and management information could be clustered in a meaningful way using cluster analysis and that this clustering approach would yield better peer groups of farms than benchmarking methods based on criteria such as country, region, breed, or breed and region. By applying mixed latent-class model-based cluster analysis to 529 North American AMS dairy farms with respect to 18 significant risk factors, 6 clusters were identified. Each cluster (i.e., peer group) represented unique management styles, challenges, and production patterns. When compared with peer groups based on criteria similar to the conventional benchmarking standards, the 6 clusters better predicted milk produced (kilograms) per robot per day. Each cluster represented a unique management and production pattern that requires specialized advice. For example, cluster 1 farms were those that recently installed AMS robots, whereas cluster 3 farms (the most northern farms) fed high amounts of concentrates through the robot to compensate for low-energy feed in the bunk. In addition to general recommendations for farms within a cluster, individual farms can generate their own specific goals by comparing themselves to farms within their cluster.

Received July 22, 2015.

Accepted March 17, 2016.

${ }^{1}$ Corresponding author: mtremblay@wisc.edu
This is very comparable to benchmarking but adds the specific characteristics of the peer group, resulting in better farm management advice. The improvement that cluster analysis allows for is characterized by the multivariable approach and the fact that comparisons between production units can be accomplished within a cluster and between clusters as a choice.

Key words: cluster analysis, automatic milking system, benchmarking, recommendation, production management

\section{INTRODUCTION}

Automatic milking systems (AMS) are increasing in popularity and number around the world (de Koning, 2010). As systems become more advanced under constraints of well-being, technical improvements, and economic feasibility, the variety in dairy management systems increases - from organic grazing to standard herds, from tie stalls to AMS, and from small family farms to large freestall herds. Even with the best technology in place, it is necessary to know one's strengths and weaknesses to make continuous improvements and set appropriate management and production goals. The dairy industry is similar to other production systems in which benchmarking is used to compare herds and motivate producers to set goals for their farm (Khade and Metlen, 1996; Boda, 2006; von Keyserlingk et al., 2012), but it is important for benchmarking to be based on the correct comparison group given the wide variety in the dairy industry.

Many dairy record systems, benchmarking programs, and benchmarking results have been published in non-peer-reviewed publications that enable producers to compare themselves with others and monitor their production progress. Benchmarking uses percentile ranks of the production values of groups of farms to compare farms within peer groups. However, grouping for conventional benchmarking is commonly limited to the use of a few factors such as farms' geographic region 
or breed of cattle. For example, the USDA's National Agricultural Statistics Service (NASS) summarizes yearly production by region or by herd size (USDA NASS, 2014). Similarly, the DHI's executive analysis "Udder Health Monitor" report compares a herd's SCC with that of herds of a similar size broken down into 3 groups: 1-199, 200-999, and >999 cows (Dairy Records Management Systems, 2014). In addition, DHI's "Herd Management Comparison" report uses breed averages (Holstein or Jersey) by region and the industry's standard goals (Dairy Records Management Systems, 2014). More advanced programs, such as DairyMetrics, can be used to select smaller comparison groups but with the additional restriction items being limited to data found in DHI reports such as SCC and milking frequency (Dairy Records Management Systems, 2012). Specific to AMS, the social network "Benchmark" (Lely Industries N.V., Maassluis, the Netherlands) allows farmers to compare performance variables to that of others in their social network or from selecting others in the same region or with the same farm size. However, these benchmarking methods rely on personal judgment to create peer groups, and the restrictions used (e.g., country, breed, region, or breed and region) do not account for the wide range of systems and conditions in today's dairy industry.

In contrast to the previously mentioned methods, cluster analysis is used to make groups of similar observations that can be based on many different variables (Borcard et al., 2011). Brotzman et al. (2015) used 16 performance values to cluster large Wisconsin dairies into 6 groups that were then characterized into best, good, and poor performance. In a similar industry, the dairy goat farming systems in Italy was successfully characterized into 3 major groups separated into 5 clusters using a cluster analysis of a variety of performance, facility, and management data (Usai et al., 2006). Clusters define neighbors not necessarily as geographic neighbors but neighbors in "similarity of farm characteristics."

Given the wide range in conditions in the dairy industry, to make comparison groups, many factors that significantly affect a herd's production ability need to be assessed simultaneously. In Brotzman et al. (2015), many other limiting factors exist, although herd size was limited to those with at least 200 cows and some environmental variation was limited by only examining Midwestern US dairy herds. In addition, many factors unique to AMS that might affect production are not included in these aforementioned benchmarking and clustering methods. For example, traffic type and the number of robots per pen have been shown to significantly affect milk production in AMS farms (Tremblay et al., 2016). Also, some criteria, such as milking frequency ( 2 or 3 times per day), do not apply to AMS because cows in an AMS are free to regulate their milking frequency individually. In addition, most benchmarking tools are based on data collected via DHI databases, which is based on measurements taken only once every 3 to 4 wk. Automatic milking systems or parlor systems and sensor technology provides an opportunity to use results collected on a daily basis.

There is a need to compare AMS farms based on relevant variables in an unbiased fashion, which is not currently being provided for these specialized farms. The goals of this study were to characterize farming patterns of AMS herds to prioritize and customize advice for producers regarding their farm management. We hypothesized that herds' production data and management information could be grouped into meaningful multivariable clusters and that this clustering approach would produce better peer groups than conventional benchmarking methods that create peer groups based on criteria such as country, region, breed, or breed and region alone. The specific aim was to perform a cluster analysis of hundreds of North American AMS dairy farms with respect to significant risk factors identified by a generalized mixed linear model. Identifying a farm's nearest neighbor in terms of production patterns and management limitations would allow advice to be tailored to these modern specialized producers.

\section{MATERIALS AND METHODS}

A total of 529 North American dairy farms with Lely Astronaut AMS (Lely Industries N.V., Maassluis, the Netherlands) had weekly data collections for $4 \mathrm{yr}$ (2011-2014), which produced 54,065 observations. A previous study found 20 variables from this data set to be significantly associated with changes in milk production $(\mathrm{kg})$ using a generalized linear mixed regression model (Tremblay et al., 2016).

Of the 20 available variables, 5 were categorical variables. The numbers of farms per categorical variable levels and variable explanations are detailed in Table 1. Traffic type (i.e., how cows move through the pen among the AMS, freestalls, and feed fence) can be free or forced. With free cow traffic, cows decide when to enter the AMS, whereas with forced cow traffic, the producer creates one-way traffic toward the AMS. The variable Traffic_Type was coded as "free" or "forced." The Robots_per_Pen variable represented the number of robots per pen of cows. By default, this variable also represents the number of cows in a pen and the pen's physical dimensions. By design, each pen will have about 60 cows per robot. For example, Robots_per_Pen of " 1 " is designed with 1 robot in a pen of about 60 cows and Robots_per_Pen of " 2 " is 
Table 1. The number of farms per categorical variable

\begin{tabular}{llr}
\hline $\begin{array}{l}\text { Categorical } \\
\text { variable }\end{array}$ & Level & $\begin{array}{r}\text { No. of } \\
\text { farms }^{2}\end{array}$ \\
\hline Traffic_Type & Free & 493 \\
& Forced & 36 \\
Robots_per_Pen & 1 & 295 \\
& 2 & 208 \\
Breed & $3+$ & 26 \\
& Holstein & 473 \\
Farm_Goal & Jersey & 15 \\
& Other & 41 \\
New_Retro & Quota (Canada) & 350 \\
& Max_Production (US) & 179 \\
& New & 266 \\
& Retro & 263 \\
\hline
\end{tabular}

${ }^{1}$ Variables: Traffic_Type $=$ how cows are allowed to move among areas of a barn. "Free" refers to a system where cows can decide when to enter the AMS and can move freely between the automatic milking system (AMS), freestalls, and the feeding area. "Forced" traffic type uses a one-way traffic system toward the AMS; Robots_per_Pen = number of AMS robots per pen; Breed = breed of cattle; Farm_Goal = operate under the "Quota" system for farms in Canada or "Max_Production" for farms in the United States that produce with the goal of maximum milk production; New_Retro = newly built or robots retrofitted in an existing barn.

${ }^{2}$ Of 529 total observations.

designed with 2 robots in a pen of about 120 cows. Breed was categorized into 3 levels: "Holstein," "Jersey" and "other." Breed "other" represents all other breeds: Ayrshire, Brown Swiss, Guernsey, Red and White, crosses, mixed, and unknown. Farm_Goal was characterized either by the "quota" system for farms in Canada or "maximum production" for farms in the United States that produce with the goal of maximum milk production. Grazing and organic farms were not used in the previous analysis of this data set because they had relatively few observations. The New_Retro variable was either "new" for AMS robots that were installed in newly built barns or "retro" for AMS robots that were retrofitted in existing barns.

Thirteen numeric AMS variables were available: Milk_Production_per_Cow_per_Day, Cows_per_Robot, Average_DIM, Concentrates, Rest_Feed, Refusals, Failures, Milkings, Milk_Speed, Boxtime, Connection_ Attempts, Robot_Free_Time, and Days_Since_Installation. The variable explanations are presented in Table 2 . The data set was previously limited to observations that had $>10$ Cows_per_Robot and $<90$ Cows_per_Robot. Observations with an Average_DIM greater than $365 \mathrm{~d}$ were also removed as outliers. All weekly numeric observations were averaged per farm to produce a final data set for clustering with one observation per farm (n $=529$ ). The summary statistics and explanations of the numeric variables are shown in Table 2 . All statistical analyses were done using the program $\mathrm{R}$ version 3.0.1 (R Development Core Team, 2013).

The variables Season and Record_Year were not included as they were not meaningful when working with farm as the unit of observation. A cluster analysis was performed using the 18 variables. Due to the mixture of continuous and categorical variables, 2 of which had more than 2 factor levels, a mixed latent-class modelbased approach was chosen (Hennig, 2010). Another benefit of model-based clustering is that normalization and scale differences among variables do not affect the outcome (Vermunt and Magidson, 2002). The method was computed by the function flexmixedruns in the $\mathrm{R}$ package fpc (Hennig, 2010). Maximum likelihood estimation was used to determine the best model and

Table 2. Numeric variables and descriptive statistics

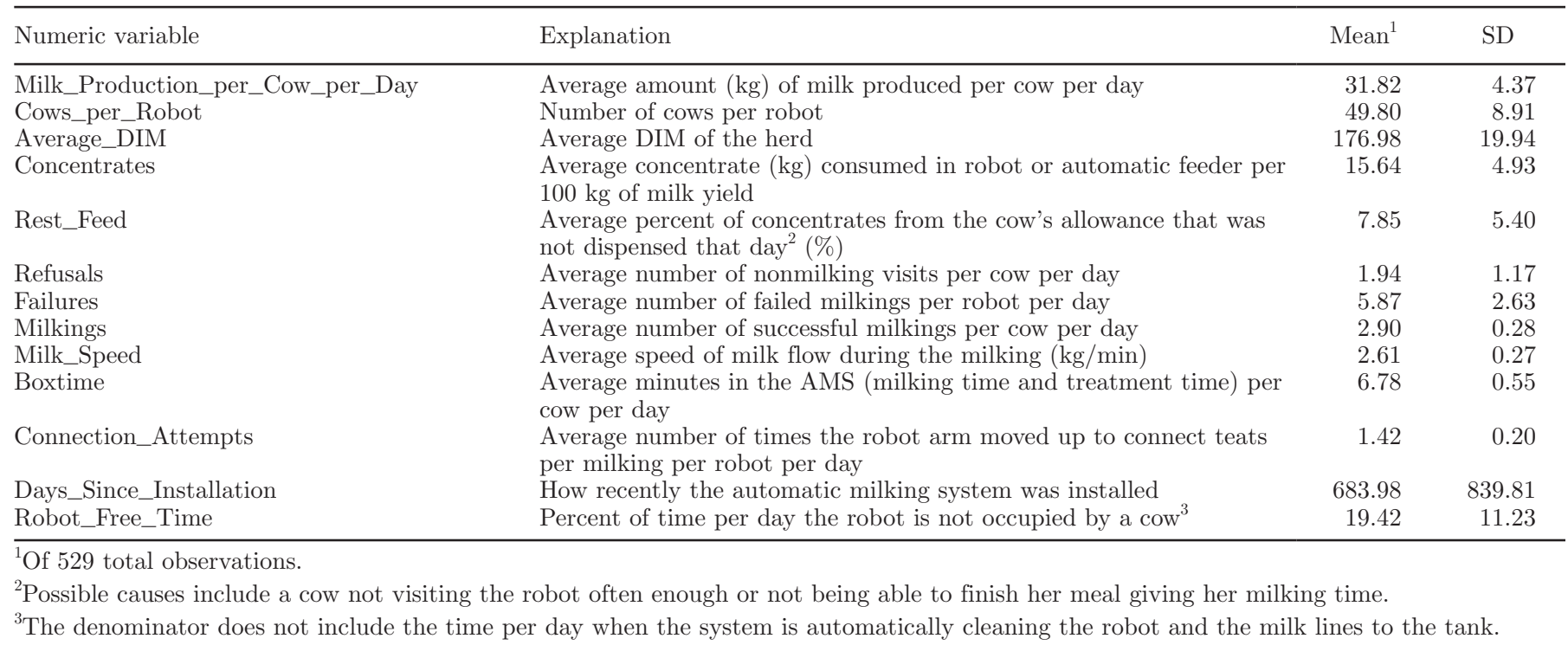


the Bayesian information criterion (BIC) determined the best number of clusters. One hundred starts of the expectation-maximization (EM) algorithm with random initialization were compared during a sensitivity analysis to optimize the model for each number of clusters between 2 and 20 (Hennig, 2010). Because only variables previously selected from Tremblay et al. (2016) were used in the cluster analysis, and the number of variables was not larger than the number of observations, the mixed latent-class model-based approach did not require further variable selection (Dean and Raftery, 2010; Poon et al., 2010).

Categorical variables were examined per cluster, and the $\chi^{2}$ test was used to test for significant changes in proportions between variable levels in each cluster compared with the entire population. Averages of the numeric production variables were calculated from all farms in each cluster. Testing for significant differences between clusters based on variables that were used in the clustering is inappropriate because cluster analysis separates observations based on these variables (Legendre and Legendre, 2012). Therefore, we did not perform significance testing of the variables' means per cluster. Average values were ranked across clusters and color-coded for visual identification in a cross table. All of the farms represented in the final data set were mapped using a heat map to keep individual farm identity anonymous. Farms in each cluster were mapped to look for geographic patterns.

To simulate commonly applied grouping methods in the industry, 4 other grouping classification were assigned based on commonly used criteria: country, breed, region and a combination of breed and region. Regions were defined as Midwest, East, Northeast and Northwest. Midwest states included Iowa, Illinois, Indiana, Michigan, Minnesota, Missouri, North Dakota, Ohio, South Dakota, and Wisconsin. East states included Massachusetts, New York, Pennsylvania, Virginia, and Vermont. Northeast provinces included New Brunswick, Nova Scotia, Ontario, and Quebec. Northwest provinces included Saskatchewan, Manitoba, Alberta, and British Columbia. There were no Jersey farms in the Northwest region and only one Jersey farm in the Eastern region, which was reassigned to the Jersey Midwest group for the breed and region classification. In addition, there was only one "other" breed farm in the East region; therefore, it was reassigned to the "other" Midwest group. In the end, there were 9 breed and region groups.

The amount of milk produced per robot per day was not used for the cluster analysis; however, it is one of the major determinants of income for dairy farms including AMS farms. Thus, the external variable Milk_Production_per_Robot_per_Day was used for validation (Aldenderfer and Blashfield, 1984; Yang, 2012) when comparing the following grouping variables for predictions: farm clusters generated by cluster analysis and groups of farms based on the conventional benchmarking criteria (i.e., country, region, breed, and a combination of region and breed). The 5 grouping variables (see Table 5) were used to predict milk production per robot per day by means of a generalized linear regression model with the number of farms per group as an offset. The fit of the regression models and their predictive ability were compared among the 5 grouping methods in addition to the null model using these criteria: log-likelihood, BIC, Akaike information criterion (AIC), mean absolute error, and root mean square error.

\section{RESULTS}

The 5 categorical variables are described in Table 1 . The 13 numeric variables used in the cluster analysis are described in Table 2. The cluster analysis resulted in a latent-class model with a log-likelihood of $-9,817.368$ with $203 \mathrm{df}$, an AIC of 20,040.74, and a BIC of 20,907.75. This model resulted in 6 clusters with an average of 88 farms per cluster (range: 50-124).

The distribution of herds among each categorical variable level was examined per cluster (Table 3). Several differences were found in the proportions of farms per variable level of each cluster compared with the overall population of 529 farms (Table 3). Compared with all the farms, cluster 1 had a higher proportion of farms with 2 or more robots per pen and farms with breeds other than Jerseys and Holsteins. Cluster 2 had a higher proportion of farms with forced traffic and Jerseys under the quota system compared with the entire population. Cluster 3 farms were exclusively under the quota system (Canadian). Cluster 4 had a high proportion of farms with 1 robot per pen compared with all farms. Cluster 5 had a high proportion of Holstein and maximum production farms in the United States, whereas cluster 6 had a high proportion of newly built barns and Holstein farms under the quota system compared with the entire population. See Table 3 for all results.

The average numeric variables values of each farm are shown per cluster in Table 4. Cluster 1 had the greatest Connection_Attempts and the most recent installation of AMS robots. Cluster 2 had the lowest average of Milk_Production_per_Cow_per_Day, Milkings, Milk_ Speed, and Connection_Attempts. The greatest average of Rest_Feed, Failures, Days_Since_Installation, and Average_DIM were present in cluster 2. Cluster 3 had the greatest average of Concentrates, and cluster 4 had the greatest average of Boxtime and lowest average 
Table 3. Number of farms (percentages in parentheses) per cluster by categorical variable $(\mathrm{n}=529)$

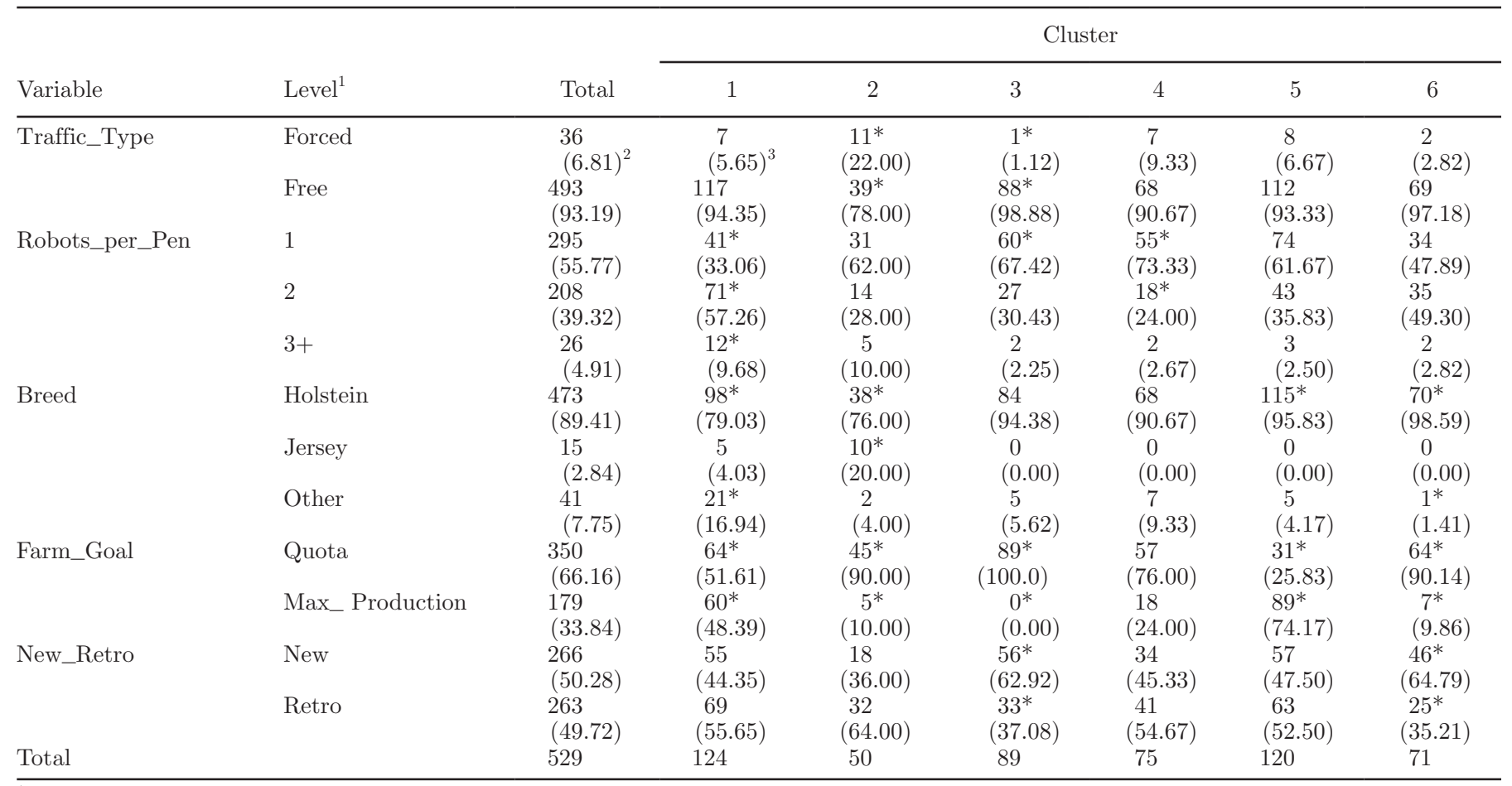

${ }^{1}$ Variables: Traffic Type $=$ how cows are allowed to move among areas of a barn. "Free" refers to a system where cows can decide when to enter the automatic milking system (AMS) and can move freely between the AMS, freestalls, and the feeding area. "Forced" traffic type uses a one-way traffic system toward the AMS; Robots_per_Pen = number of AMS robots per pen; Breed = breed of cattle; Farm_Goal = operate under the "Quota" system for farms in Canada or "Max_Production" for farms in the United States that produce with the goal of maximum milk production; New_Retro $=$ newly built or retro fitted barn; Years_Since_Install $=$ how recently $(y r)$ the AMS was installed; Robot_Free_Time = percent of time per day the robot is not occupied; Record_Year = year at the time of record; Season = "Winter" was classified as December through February; "Spring" as March through May, "Summer" as June through August, and "Fall" was classified as September through November.

${ }^{2}$ Percent of total farms.

${ }^{3}$ Percent of farms per cluster.

*Significantly different compared with the total population $(P<0.05)$.

of Robot_Free_Time. Milk_Production_per_Cow_ per_Day, Milk_Speed, and Cows_per_Robot had the greatest average in cluster 5 . Cluster 5 herds had the lowest average of Concentrates, Rest_Feed, Refusals, and Average_DIM. Cluster 6 had the lowest Cows_ per_Robot, Boxtime, and Failures; Robot_Free_Time, Milkings, and Refusals had lowest average in cluster 6 .

A map of the 529 farms is shown in Figure 1. The highest concentrations of farms were in the Midwest United States (Minnesota and Wisconsin), southern Ontario (between Detroit and Toronto), and lower Quebec (between Ottawa and Quebec City). Other concentrations of farms were located outside Vancouver, outskirts of Winnipeg, between Edmonton and Calgary, and eastern Pennsylvania.

Cluster 5 herds were mainly located in the Midwest (see Figure 2E). Cluster 2 and 6 farms were centered in the east, whereas cluster 1 and 4 farms had an even distribution in all concentrations of farm locations (see Figure 2A and D). The most northern cluster of the study group was cluster 3 (see Figure 2C).
Table 5 describes the results of the 5 regression models predicting production per robot per day using the grouping methods as independent variables. The cluster analysis external validation model had the best fit with the largest log-likelihood, and lowest residual deviance, AIC, BIC, mean absolute error, and root mean square error.

\section{DISCUSSION}

The need to compare industry standards for AMS is great because of the investments made in these specialized systems. Current benchmarking tools do not compare AMS based on all relevant variables or lend specialized advice based on multiple variables simultaneously. Eighteen variables significantly associated with milk production per day (Tremblay et al., 2016) were used to cluster 529 automatic milking farms. We compared the predictive ability of 6 farm clusters generated by cluster analysis to groups of farms based on the conventional benchmarking criteria (i.e., country, 


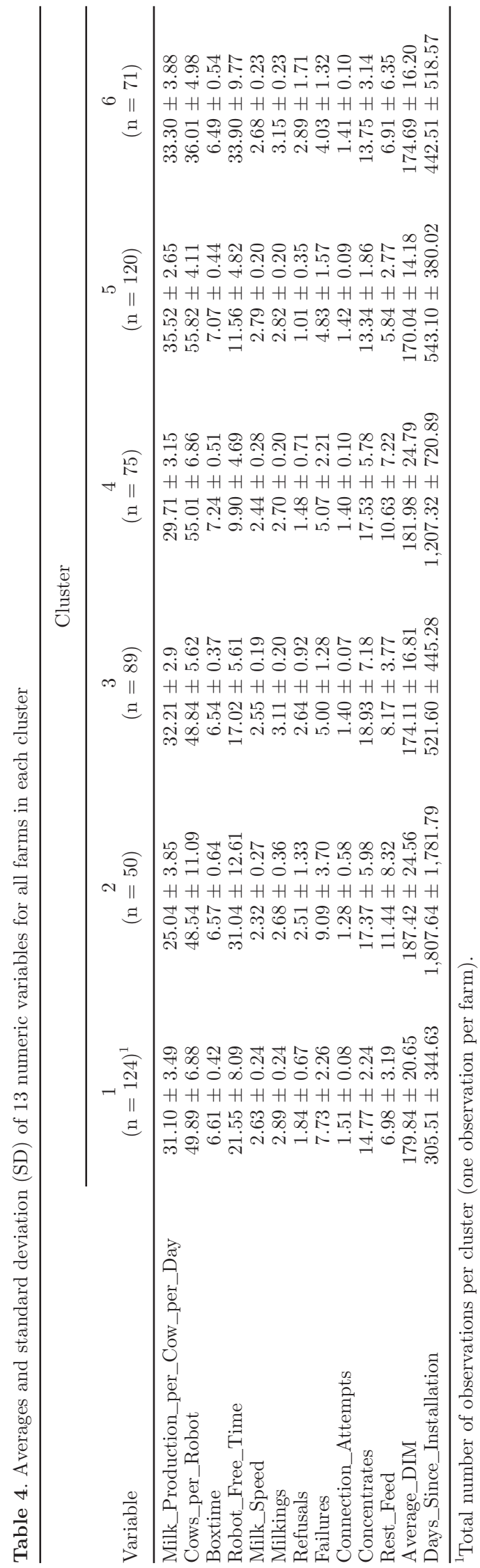

region, breed, and a combination of region and breed). Cluster analysis comparison groups were better at predicting milk production per robot than benchmarking comparison groups. Better AMS peer groups allow for improved comparison within groups because farms within clusters are more similar compared with the general average across all farms. Allowing farms to set appropriate goals according to individual situations (e.g., recent robot installation, environmental, facilities constraints) minimizes the potential for goals to be unrealistic. Each of the 6 clusters had different farm characteristics and therefore the clusters can benefit from different recommendations following on the priorities of the cluster member herds. Next, we will discuss the characteristics and recommendations per cluster.

\section{Cluster 1}

On average, cluster 1 farms had the most recent robot installations (see Table 4). Recent installation has been shown to significantly decrease milk production compared with systems that have been in place for $>4$ yr (Tremblay et al., 2016). As cluster 1 herds become established during their start-up period, they will need to continue selecting cows that are best for AMS milking.

Cluster 1 farms represented breeds other than Holstein (21/41 "other" breed farms, 5/15 Jersey breed farms) with high average Failures and Connection_Attempts (see Table 4). Although a previous analysis of this data set did not find a significant difference in Milk_Production_per_Cow_per_Day between the "other" and "Holstein" breed groups, this might be a result of all the other breeds having been grouped together (Ayrshire, Brown Swiss, Holstein Crosses, Guernsey, Red and White, mixed; Tremblay et al., 2016). When breeds were examined separately, average milk yield varied among breeds (Cerbulis and Farrell, 1975; VanRaden and Sanders, 2003; USDA-AIPL, 2013). Ayrshire, Jersey, and Holstein breeds were also found to vary in milking speed and milking temperament (Sewalem et al., 2010). In addition, the difference between small breeds (Jersey, Guernsey, Ayrshire) and large breeds (Holstein, Brown Swiss) could affect how cows fit and align in a milking robot, and their difference in udder conformation could make one breed, such as a large or small breed, more prone to failed connections (Norman et al., 1988; Rodenburg, 2002; Capper et al., 2009). Therefore, it might not be advisable to formulate production goals for all "other" breed herds based on subsets that include "Holstein" breed herds. It is recommended that cluster 1 herds examine whether their settings are correctly adjusted according to their non-Holstein cows. 


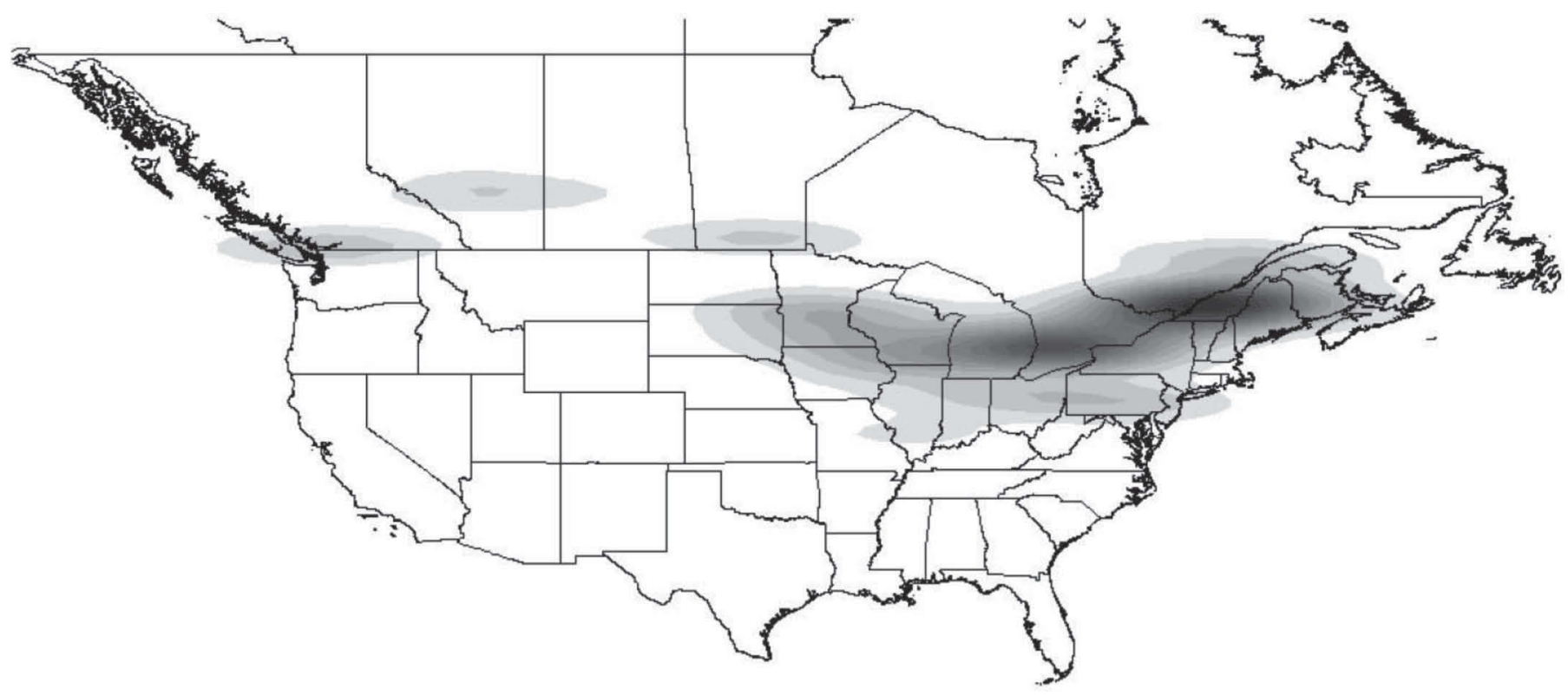

Figure 1. Heat map of all farm locations $(\mathrm{n}=529)$.

\section{Cluster 2}

Cluster 2 consisted of farms with the lowest Milk Production_per_Cow_per_Day and Milk_Speed. Cluster 2 also had the highest average Failures (see Table 4). This cluster had 10 of the 15 Jersey breed farms. Jersey farms most likely fit in best with low-producing Holstein herds because of their lower milk yield on an equal boxtime, which results in lower average milk speed (Prendiville et al., 2010; Tremblay et al., 2016). These low-production Holstein farms in cluster 2 could be characterized as farms with mediocre management, farms that have made a clear choice for low input, or farms where the major income is from something other than dairy production.

Cluster 2 farms had the highest proportion of forced Traffic_Type. Forced traffic type has been shown to result in significantly less milk per cow and per robot per day compared with free traffic type (Tremblay et al., 2016). The recommendation for these farms is to check with their robot consultant whether it is feasible to open up all space to the robots and change the gates in the barn to move into a free cow traffic system.

If a cluster 2 farm is faced with high Rest_Feed, they should assess feed allowance settings to ensure that each cow is allotted sufficient milkings per day. This is important to allow enough time to finish their concentrate in the robot. These farms may also need to increase the density of the concentrate feed (for faster energy intake) or add additional feed dispensers in the robot for high-density concentrates.

\section{Cluster 3}

Cluster 3 farms fed high levels of concentrates and were generally the most northern farms of the study group (see Figure 2C). Their environment and feed availability offer unique challenges, as they can offer only basic forages at the feed bunk compensated with additional higher concentrate feed in the robot; therefore, they should be compared with other farms facing similar challenges. It is especially important for cows in these farms to receive all of their allotted concentrate. These farms could add separate automatic feeding stations outside of the robot so that cows can finish their allowance in between milkings.

\section{Cluster 4}

A high proportion of cluster 4 farms had only 1 robot per pen. These farms need to make sure that the downtime or inaccessibility of the robot is minimized, whereas farms with 2 or more robots per pen can shut down one robot for daily maintenance and keep milking cows in the other robot (Tremblay et al., 2016). Also, a single robot per pen has a greater effect on timid cows compared with 2 robots because a single robot does not allow timid cows additional opportunities for milking when dominant cows crowd the single robot. Timid cows have been shown to wait longer to go to the robot compared with higher-ranking cows (Ketelaar-de Lauwere et al., 1996; Thune et al., 2002; Melin et al., 2006), and the presence of a single robot does not allow 

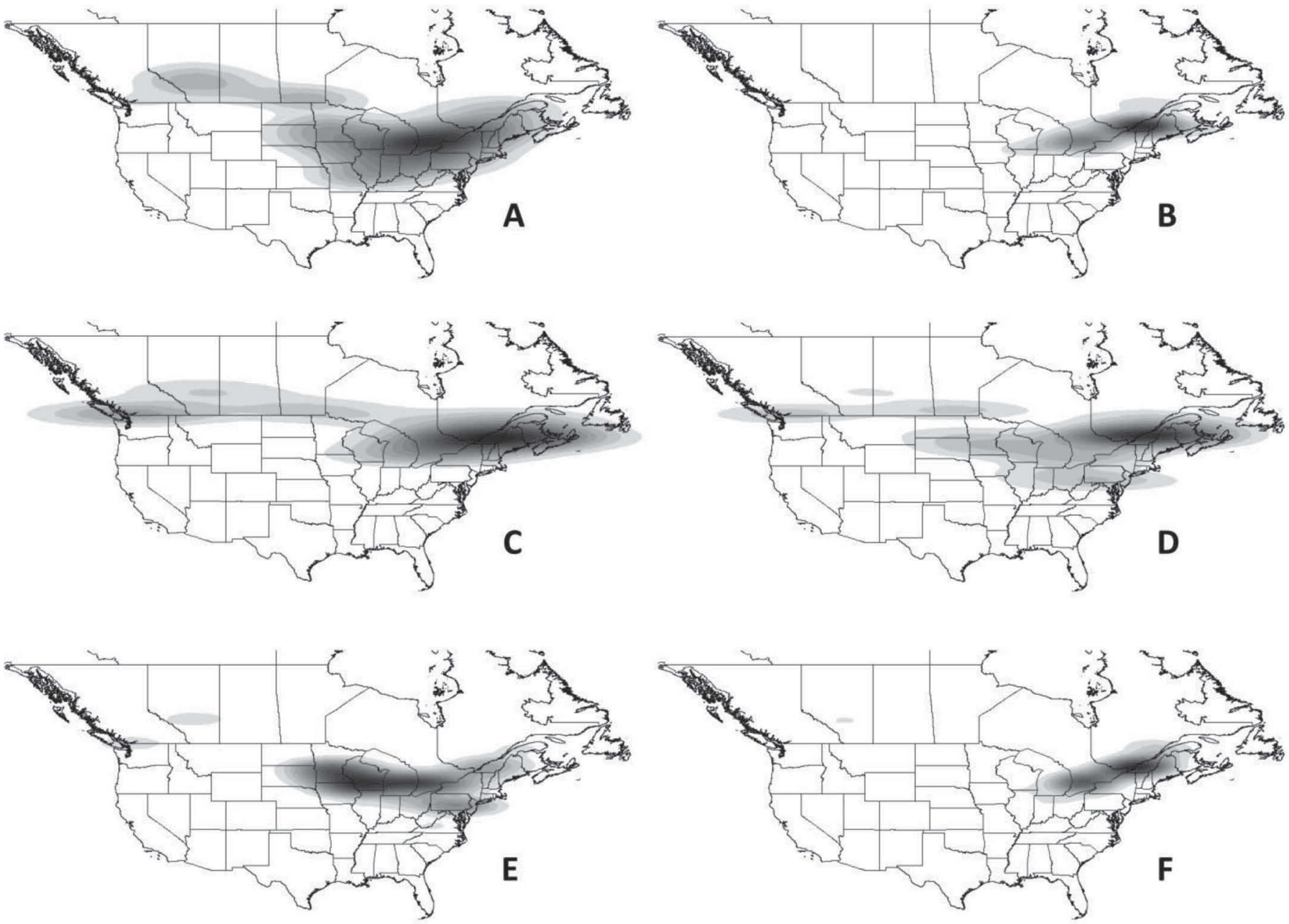

Figure 2. Heat map of farm location by cluster: $(A)$ cluster $1(\mathrm{n}=124),(B)$ cluster $2(\mathrm{n}=50),(C)$ cluster $3(\mathrm{n}=89)$, (D) cluster 4 (n = $75),(\mathrm{E})$ cluster $5(\mathrm{n}=120)$, and $(\mathrm{F})$ cluster $6(\mathrm{n}=71)$.

Table 5. Goodness of fit parameters and predictive ability of the linear regression models

\begin{tabular}{|c|c|c|c|c|c|c|c|}
\hline Model $^{1}$ & df & $\log \operatorname{Lik}^{2}$ & Res. Dev. ${ }^{3}$ & $\mathrm{AIC}^{4}$ & $\mathrm{BIC}^{5}$ & MAE $^{6}$ & $\mathrm{RMSE}^{7}$ \\
\hline Breed and region & 520 & $-3,806.23$ & $55,030,856$ & $7,632.5$ & $7,675.2$ & 262.7 & 322.5 \\
\hline Country & 527 & $-3,827.56$ & $59,651,230$ & $7,661.1$ & $7,673.9$ & 271.9 & 335.8 \\
\hline Null model $^{8}$ & 528 & $-3,867.35$ & $69,336,252$ & $7,738.7$ & $7,747.3$ & 297.2 & 362.0 \\
\hline
\end{tabular}

${ }^{1}$ Linear regression model with Milk_Production_per_Robot_per_Day (kg) as the dependent variable, comparison groups (cluster, breed and region, region, breed, country) as a discrete independent variable, and an offset as the number of farms per comparison group.

${ }^{2}-2 \times \log$-likelihood.

${ }^{3}$ Residual deviance.

${ }^{4}$ Akaike information criterion.

${ }^{5}$ Bayesian information criterion.

${ }^{6}$ Mean absolute error.

${ }^{7}$ Root mean square error.

${ }^{8}$ Milk_Production_per_Robot_per_Day $\sim 1$. 
these cows alternative opportunities for milking. This effect on a small number of cows can severely affect the overall average of the herd's AMS variable values. Advice for cluster 4 farms includes identifying individual cows that are not suited for AMS milking (e.g., too timid for milking in a pen with a single robot or need to be fetched often).

\section{Cluster 5}

Compared with the entire population of 529 farms, cluster 5 had a higher proportion of Holstein breed farms, farms located in the Midwest, and farms with a Farm_Goal of maximum production (see Table 3 and Figure 2E). They had, on average, the highest Milk Production_per_Cow_per_Day of all the clusters (see Table 4). This cluster was the most intense in terms of Cows_per_Robot but continued to meet the recommendations for average milkings of $>2.6$ milkings per cow per day (Sitkowska et al., 2015). As the highest producing farms, cluster 5 farms had well-run AMS in place. Customized advice to cluster 5 should consist of small adjustments; for example, decreasing Failures, because failures can disturb a cow's time budget (Stefanowska et al., 2000). Milking failures lead to interrupted milkings and have been shown to cause milk leakage, a potential risk factor for mastitis (Elbers et al., 1998; Stefanowska et al., 2000). In addition, these farms will need to select cows for high milk speed and cow-robot efficiency to gain milk production.

\section{Cluster 6}

Clusters 6 farms had high Milk_Production_per_ Cow_per_Day and Milk_Speed averages but had a low average number of Cows_per_Robot (see Table 4). The low number of Cows_per_Robot in cluster 6 could reflect low available milk quotas, given that cluster 6 had a higher proportion of farms located in Canada compared with the entire population (Table 3). A low ratio of Cows_per_Robot negatively affects Milk_Production_ per_Robot_per_Day and Boxtime while increasing Refusals, because there is a large surplus of robot capacity (Tremblay et al., 2016). Although extreme values exist, secondary to their values of Cows_per_Robot, all other values were well controlled and they had the lowest average Failures of all clusters. Advice for cluster 5 and cluster 6 , given the limited available quota, would focus on optimizing the efficiency of milk production by producing more milk with less cows and resources such as feed, cost of operation, and reproduction.

Although the 18 variables used for the clustering of farms were readily available through the Lely T4C (Time for Cows) herd management system (Lely In- dustries N.V.) and represent important performance indicators for dairy farms, other variables could be included in a larger scale study. For instance, the many breed variations mentioned above suggest that breaking down the "Breed" variable would add to the analysis. Variables pertaining to animal health, herd genetics, farm economics, reproduction, facilities, and feeding management could be examined as potential risk factors for different production levels. Including the grazing and organic farms and data from other AMS companies and countries would also broaden the impact of a future data analysis project. In addition to increasing the number of risk factors included in the cluster analysis, follow-up surveys could be used to analyze each cluster in more depth for the sake of validating the outcomes of the current study.

Adding these techniques to current benchmarking and management tools available to individual farms would greatly benefit the farms' management but would also raise some challenges. For example, missing data would need to be addressed to ensure quality without eliminating participants from the analysis. Data imputation techniques could be used to estimate values for missing data. Some degree of misclassifications (i.e., assigning a farm to an inappropriate cluster) will always be present when clustering is applied, irrespective of the choice of technique. Also, as data sets evolve with time, the most appropriate clustering technique might change. The clusters describe the average farm within a cluster, and caution must be taken in interpreting the results of this study to one individual farm. The current results regarding characteristics of the clusters are meant as decision aids and orientation for customized expert advice in the field of AMS dairy herds.

\section{CONCLUSIONS}

A cluster analysis of 529 North American AMS herds with respect to significant predictors for milk production identified 6 clusters of production patterns and management characteristics. Unlike current benchmarking grouping techniques, cluster analysis produces more appropriate peer groups among diverse farms. Each cluster exhibited a unique multivariable production pattern and management style that can result in distinct recommendations per farm. In addition, farms can set realistic goals according to comparisons within each cluster.

\section{ACKNOWLEDGMENTS}

We thank Lely North America (Pella, IA) for their financial support of this study. We gratefully acknowledge the expertise of Rik van der Tol (Lely Industries 
N.V., Maassluis, the Netherlands) for his assistance in the planning of this project.

\section{REFERENCES}

Aldenderfer, M. S., and R. K. Blashfield. 1984. Cluster Analysis. Quantitative Applications in the Social Sciences. Vol. 44. Sage Publications, Beverly Hills, CA.

Boda, G. 2006. Benchmarking dairy information using interactive visualization for dairy farm decision making. MSc Thesis. Department of Animal Science, McGill Univ., Canada.

Borcard, D., F. Gillet, and P. Legendre. 2011. Numerical Ecology with R. Springer, New York, NY.

Brotzman, R. L., N. B. Cook, K. Nordlund, T. B. Bennett, A. Gomez Rivas, and D. Döper. 2015. Cluster analysis of Dairy Herd Improvement data to discover trends in performance characteristics in large Upper Midwest dairy herds. J. Dairy Sci. 98:3059-3070. http://dx.doi.org/10.3168/jds.2014-8369.

Capper, J. L., R. A. Cady, and D. E. Bauman. 2009. The environmental impact of dairy production: 1944 compared with 2007. J. Anim. Sci. 87:2160-2167. http://dx.doi.org/10.2527/jas.2009-1781.

Cerbulis, J., and H. M. Farrell Jr.. 1975. Composition of milks of dairy cattle. I. Protein, lactose, and fat contents and distribution of protein fraction. J. Dairy Sci. 58:817-827. http://dx.doi.org/10.3168/ jds.S0022-0302(75)84644-3.

Dairy Records Management Systems. 2012. Dairy Metrics. Accessed May 2, 2015. http:// www.drms.org/dairymetricsinfo.aspx?node_ id=Dflt6.

Dairy Records Management Systems. 2014. DHI Report Options Accessed July 16, 2015. http://www.drms.org/pdf/materials/ optman.pdf.

de Koning, C. J. A. M. 2010. Automatic milking-A common practice on dairy farms. Pages 52-67 in Proc. First North American Conference on Precision Dairy Management, Toronto, Canada. Omnipress, Madison, WI.

Dean, N., and A. E. Raftery. 2010. Latent class analysis variable selection. Ann. Inst. Stat. Math. 62:11-35. http://dx.doi.org/10.1007/ s10463-009-0258-9.

Elbers, A. R. W., J. D. Miltenburg, D. De Lange, A. P. P. Crauwels, H. W. Barkema, and Y. H. Schukken. 1998. Risk factors for clinical mastitis in a random sample of dairy herds in the southern part of the Netherlands. J. Dairy Sci. 81:420-426. http://dx.doi. org/10.3168/jds.S0022-0302(98)75592-4.

Hennig, C. 2010. fpc: Flexible Procedures for Clustering. Version 2.0.3. https://cran.r-project.org/web/packages/fpc/index.html.

Ketelaar-de Lauwere, C. C., S. Devir, and J. H. M. Metz. 1996. The influence of social hierarchy on the time budget of cows and their visits to an automatic milking system. Appl. Anim. Behav. Sci. 49:199-211.

Khade, A. S., and S. K. Metlen. 1996. An application of benchmarking in the dairy industry. Benchmark. Qual. Manag. Technol. 3:34-41.

Legendre, P., and L. F. Legendre. 2012. Numerical Ecology. Vol. 24. Elsevier, Oxford, UK.

Melin, M., G. G. N. Hermans, G. Pettersson, and H. Wiktorsson. 2006 Cow traffic in relation to social rank and motivation of cows in an automatic milking system with control gates and an open waiting area. Appl. Anim. Behav. Sci. 96:201-214.

Norman, H. D., R. L. Powell, J. R. Wright, and B. G. Cassell. 1988. Phenotypic and genetic relationship between linear functional type traits and milk yield for five breeds. J. Dairy Sci. 71:1880-1896. http://dx.doi.org/10.3168/jds.S0022-0302(88)79758-1.
Poon, L. K. M., N. L. Zhang, T. Chen, and Y. Wang. 2010. Variable selection in model-based clustering: To do or to facilitate. Pages 887-894 in Proc. 27th International Conference on Machine Learning. ACM, New York, NY.

Prendiville, R., K. M. Pierce, and F. Buckley. 2010. A comparison between Holstein-Friesian and Jersey dairy cows and their F1 cross with regard to milk yield, somatic cell score, mastitis, and milking characteristics under grazing conditions. J. Dairy Sci. 93:27412750. http://dx.doi.org/10.3168/jds.2009-2791.

R Development Core Team. 2013. R: A Language and Environment for Statistical Computing. R Foundation for Statistical Computing, Vienna, Austria. http://www.R-project.org/.

Rodenburg, J. 2002. Robotic milkers: What, where . . . and how much!!?? Pages 1-18 in Proc. Ohio Dairy Management Conf., Columbus, OH. Ohio State University Extension, Columbus.

Sewalem, A., F. Miglior, and G. J. Kistemaker. 2010. Analysis of the relationship between workability traits and functional longevity in Canadian dairy breeds. J. Dairy Sci. 93:4359-4365. http://dx.doi. org/10.3168/jds.2009-2969.

Sitkowska, B., D. Piwczyński, J. Aerts, and M. Waśkowicz. 2015. Changes in milking parameters with robotic milking. Arch. Anim. Breed. 58:137-143. http://dx.doi.org/10.5194/aab-58-137-2015.

Stefanowska, J., M. Plavsic, A. H. Ipema, and M. M. W. B. Hendriks. 2000. The effect of omitted milking on the behaviour of cows in the context of cluster attachment failure during automatic milking. Appl. Anim. Behav. Sci. 67:277-291. http://dx.doi.org/10.1016/ S0168-1591(00)00087-3.

Thune, R. Ø., A. M. Berggren, L. Gravås, and H. Wiktorsson. 2002. Barn layout and cow traffic to optimise the capacity of an automatic milking system. Pages 45-50 in Proc. 1st N. Am. Conf. Robotic Milking, Toronto, Canada. J. McLean, M. Sinclair, and B. West, ed. Wageningen Press, Wageningen, the Netherlands.

Tremblay, M., J. P. Hess, B. M. Christenson, K. K. McIntyre, B Smink, A. J. van der Kamp, L. G. de Jong, and D. Döpfer. 2016. Factors associated with increased milk production for automatic milking systems. J. Dairy Sci. 99:3824-3837. http://dx.doi. org/10.3168/jds.2015-10152.

Usai, M. G., S. Casu, G. Molle, M. Decandia, S. Ligios, and A. Carta. 2006. Using cluster analysis to characterize the goat farming system in Sardinia. Livest. Sci. 104:63-76. http://dx.doi. org/10.1016/j.livsci.2006.03.013.

USDA-AIPL (Animal Improvement Program Laboratories). 2013. USDA summary of 2013 herd averages (DHI report K-3). Accessed July 16, 2015. https://www.cdcb.us/publish/dhi/dhi14/hax.html.

USDA-NASS (National Agricultural Statistics Service). 2014. Quick Stats Database. Accessed July 16, 2015. http://quickstats.nass. usda.gov/.

VanRaden, P. M., and A. H. Sanders. 2003. Economic merit of crossbred and purebred US dairy cattle. J. Dairy Sci. 86:1036-1044 http://dx.doi.org/10.3168/jds.S0022-0302(03)73687-X.

Vermunt, J. K., and J. Magidson. 2002. Latent class cluster analysis. Pages 89-106 in Applied Latent Class Analysis. Vol 11. J. A. Hagenaars and A. L. McCutcheon. Cambridge University Press, New York, NY

von Keyserlingk, M. A. G., A. Barrientos, K. Ito, E. Galo, and D. M. Weary. 2012. Benchmarking cow comfort on North American freestall dairies: Lameness, leg injuries, lying time, facility design and management, for high producing Holstein dairy cows. J. Dairy Sci. 95:7399-7408. http://dx.doi.org/10.3168/jds.2012-5807.

Yang, R. 2012. A hierarchical clustering and validity index for mixed data. PhD Thesis. Department of Industrial and Manufacturing Systems Engineering, Iowa State University, Ames. 